\title{
PREVENÇÃO DA EVOLUÇÃO DO PAPILOMA VÍRUS HUMANO: UMA INVESTIGAÇÃO COM MULHERES PORTADORAS DO HPV
}

\author{
PREVENTION OF THE EVOLUTION OF PAPILOMA HUMAN VIRUS: \\ AN INVESTIGATION WITH WOMEN PHV CARRIERS \\ PREVENCIÓN DE LAEVOLUCIÓN DEL PAPILOMA VIRUS HUMANO: \\ UNA INVESTIGACIÓN COM MUJ ERES PORTADORAS DELHPV
}

Maria Grasiela Teixeira Barroso* Maria Isis Freire de Aguiar**

\begin{abstract}
RESUMO: Estudos sobre doenças sexualmente transmissíveis mostram que $90 \%$ das mulheres com neoplasia intra-epitelial cervical são portadoras do Papiloma Vírus Humano - HPV. O bjetivou-se investigar a prevenção da evolução do HPV em mulheres no contexto cultural da família. Utilizou-se uma abordagem etnográfica, tendo como apoio teórico Ludke e André (1986), durante as fases de exploração, decisão e descoberta. Através de uma atividade participativa e dialogada, 25 mulheres foram entrevistadas. Percebeu-se que o HPV causou um impacto muito forte na estrutura familiar e que a maioria das mulheres não contou com o apoio de seus parceiros no tratamento. Concluiu-se pela importância de trabalhar a educação em saúde em torno do comportamento sexual das pessoas, com a finalidade de reduzir a contaminação pelo HPV.
\end{abstract}

PALAVRAS CHAVE: Doenças sexualmente transmissíveis; Família; Papillomavírus humano

\section{INTRODUÇÃO}

Procedeu-se a uma reflexão sobre a evolução do P apiloma Vírus Humano - HPV, a partir da complexidade das Doenças Sexualmente Transmissíveis - DST.

A sexualidade está sendo mal explorada e conduzida de forma desequilibrada. As relações sexuais ocorrem, muitas vezes, ocasionalmente, sem interesses emocionais e sem responsabilidades, expondo as pessoas a riscos que poderiam ser evitados. As práticas sexuais não convencionais sem proteção também têm sido um fator importante no alto índice de DST nos últimos anos (Ribeiro, 1998).

Constatou-se, por meio da literatura, que no mundo antigo as verrugas genitais já eram reconhecidas como DST. Com o surgimento de epidemias de gonorréia e sífilis na Idade Média, renovou-se o interesse pela temática das DST, mas ainda não se evidenciavam distinções entre as causas das diversas lesões da área genital. Somente a partir da década de 1970 confirmou-se a transmissibilidade entre verrugas genitais e cutâneas (J acynto e Almeida Filho, 1994).

Consideradas como doenças epidêmicas, as DST representam um desafio para a saúde pública, em virtude dos crescentes índices alcançados em todos os segmentos da sociedade. Atualmente, a infecção pelo HPV é uma das DST mais freqüentes, atingindo, principalmente, mulheres jovens (R ibeiro, 1998).

O HPV é o agente etiológico do condiloma acuminado, patologia caracterizada pelo aparecimento de verrugas na região genital e/ou anal. As lesões causadas na pele são consideradas benignas e de fácil tratamento se descobertas no início.

Recebido em 22/10/01 aceito em 16/09/02

* Professor Emérito/Titular/Livre Docente em Administração e Exercício da Enfermagem, da Universidade Federal do Ceará - Brasil Fone: (0XX85) 2240659 E-mail: grasiela@ ufc.br

* Estudante do Curso de Graduação em Enfermagem e bolsista de Iniciação Científica (CNPq-PIBIC), da Universidade Federal do Ceará - Brasil Fone: (0XX85) 99510498 E-mail: isis_aguiar@yahoo.com.br 
Além da discriminação, a mulher portadora de DST pode sofrer várias complicações, como contrair uma Doença Inflamatória Pélvica - DIP, esterilidade, aborto involuntário, gravidez ectópica, parto prematuro e câncer de colo de útero (Barbosa, 1995). Entretanto, o fator mais preocupante é a associação do HPV ao câncer de colo do útero. Estudos mostram que $90 \%$ das mulheres com Neoplasia Intra-epitelial Cervical - NIC são portadoras do vírus HPV (Ribeiro, 1998).

Hoje, sabe-se que a infecção pelo HPV tem sido preocupante frente a outras DST, podendo ser assintomática ou manifestar-se pela presença de verrugas na área externa do órgão genital, vagina, colo uterino e ânus. 0 vírus é altamente transmissível e encontra-se presente em lesões pré-cancerosas e cancerosas da cérvix uterina (Vaitsman, 1998). Sendo o HPV transmitido sexualmente, é influenciado por fatores comportamentais, culturais e econômicos determinantes das relações sexuais.

Os valores culturais e o estilo de vida exercem forte influência no enfrentamento da doença nos aspectos que envolvem diretamente a mulher e o parceiro contaminados por HPV. Sob esse prisma, é importante que sejam considerados a cultura e o contexto familiar onde se encontram seus valores culturais e suas condições de vida (Ribeiro, 1998).

A cultura condiciona a visão de mundo da pessoa "O modo de ver o mundo, as apreciações de ordem moral são posturas corporais, são produtos de uma herança cultural" (Laraia, 1997).

A herança cultural está presente nos diversos campos da vida do indivíduo. A formação do homem é influenciada por fatores familiares, sociais, culturais e pelas suas vivências. No campo da sexualidade não é diferente. A atividade sexual ultrapassa, de longe, suas raízes biológicas, é ampla e difusa, disciplinada apenas pelas interdições socioculturais.

Segundo Ramadam e Abdo (2001) o ser humano tem a existência marcada pelo signo do sexo e seus códigos. Desde o nascimento, o sexo anatômico já determina a identidade civil, a que se agregam padrões de comportamento.

Portanto, os hábitos, os comportamentos e reações, a forma como é vivenciada a sexualidade e a maneira de enfrentar as situações ligadas à sexualidade fazem parte da cultura do ser.

Algumas medidas de controle referentes ao comportamento sexual são consideradas importantes para prevenir a evolução do quadro de infecção pelo HPV, como a limitação no número de parceiros, abstinência sexual durante a terapêutica, tratamento do parceiro e o uso da camisinha (J acynto e Almeida Filho, 1994).

Uma medida preventiva de destaque tem sido identificar precocemente lesões viróticas da vulva. A pesquisa de co-fatores oncogênicos é também importante na identificação da doença.

Diante da problemática exposta, sentimos a necessidade de investigar as possibilidades de prevenção da evolução do HPV em mulheres portadoras da infecção, considerando o contexto cultural do universo da pesquisa.

Diante do problema apresentado, a pesquisa teve como objetivos: investigar a prevenção da evolução do HPV em mulheres portadoras da doença, identificar a repercussão do HPV no contexto cultural da família e refletir sobre a necessidade de um programa de prevenção das DST, com enfoque ao HPV. Foram ressaltados os fatores: socio-econômicos, socio-políticos, socioculturais e psicossociais. Mesmo sendo esses fatores fortes determinantes da doença, o estudo está centralizado no fator sociocultural, sem perder de vista os outros fatores.

\section{METODOLOGIA}

Trata-se de uma pesquisa etnográfica, com apoio metodológico em Ludke e André (1986) e André (2001), nas fases de exploração, decisão e descoberta. Para Leininger (1991), a etnografia, na mais simples e extensa compreensão, pode ser entendida como um processo sistemático de observação detalhada, descrição, documentação e análise de estilos de vida ou padrões culturais das pessoas ...

Barroso, Sousa e Frota (2000) consideram que "A etnografia é, ao mesmo tempo, ciência e arte, que busca descobrir como os informantes conceituam o seu mundo. É muito mais do que descobrir o quê as pessoas sabem ou conhecem, pois, é a própria descoberta de como pessoas têm organizado este conhecimento". 
Nesta perspectiva, a pesquisa enfocou práticas, hábitos, crenças, valores, linguagens e significados de um grupo de mulheres portadoras de HPV, visando a compreender seu modo de viver dentro da problemática no contexto da doença.

As participantes do estudo foram mulheres que utilizam o Serviço de Doenças Sexualmente Transmissíveis de uma instituição de referência para prevenção de câncer no Ceará. Foram selecionadas 25 mulheres a partir dos seguintes critérios de inclusão: serem portadoras do HPV, estarem em idade fértil e aceitarem participar da investigação.

A pesquisa foi desenvolvida no período de agosto de 2000 a julho de 2001, utilizando como instrumentos: Observação-Participante, registro em Diário de Campo e Entrevista Intensiva.

A Observação-Participante ocorreu a partir da interação das pesquisadoras com as participantes do estudo desde o início da investigação, quando, após observação e conhecimento da realização da Consulta de Enfermagem em DST, foi possível participar ativamente do seu processo, conversando com as clientes sobre os procedimentos, detectando casos de HPV, dialogando com as clientes e prestando apoio psicológico. Posteriormente, ampliou-se a interação com as clientes durante o tratamento de HPV.

O Diário de Campo foi utilizado em todos os momentos de observação e interação com as participantes para registro dos acontecimentos e contexto cultural das mesmas através de seus comportamentos, reações, crenças e descrição do estilo de vida e padrões de cultura.

As entrevistas tiveram a finalidade de aprofundar as questões surgidas no decorrer do estudo e esclarecer os problemas observados. Foram realizadas a partir da seguinte questão norteadora: Relate como a mulher pode se prevenir da evolução do HPV?, e subquestões: O que você sentia quando procurou o serviço?; Você sabe qual a doença que você tem?; J á tinha aparecido antes?; Fale sobre essa doença e outras que você já tenha tido anteriormente; Quais as doenças que as mulheres pegam, principalmente pelo sexo?; Que conhecimento você tem sobre as DST e sua experiência ao ter a doença?; O seu relacionamento sexual permaneceu o mesmo?; Mudou alguma coisa na família?; Como pensa em prevenir as DST/HPV e suas complicações?; Você gostaria de receber mais informações sobre o assunto?

Dessa forma, houve interação constante dos pesquisadores com o objeto pesquisado, pressuposto básico da pesquisa etnográfica.

Estas fases se inter-relacionaram em todas as etapas da coleta e análise dos dados, acompanhadas da Observação-Participante, com transformações ocorrendo no processo da investigação.

Foi utilizada a análise categorial de Bardin (1977) para confirmação dos resultados, organizados de forma descritiva.

Em todas as etapas foram cumpridos os Aspectos Éticos da Pesquisa Envolvendo Seres Humanos, conforme a legislação em vigor (Resolução 196/96 do Conselho Nacional de Saúde).

\section{RESULTADOS}

\section{EXPLORAÇÃO- ENTRADA NO CAMPO}

Esta primeira fase da pesquisa envolveu a seleção e definição de problemas e a escolha do local de execução da pesquisa. Teve início em agosto de 2000, quando se realizaram contatos com o Instituto de Prevenção do Câncer do Ceará - IPCC, sendo apresentados o projeto e solicitação para entrada no campo.

Inicialmente, buscou-se conhecer o funcionamento do serviço, constatou-se que este atende através de demanda espontânea com fluxo intenso, recebendo ainda encaminhamentos de outros serviços de saúde.

As clientes passam primeiramente pela consulta odontológica para investigação de lesões na cavidade oral, principalmente aquelas relacionadas a DST ou sugestivas de câncer. Posteriormente, são encaminhadas ao Ambulatório de Enfermagem em DST para a realização de Exame Citopatológico Ginecológico (ou Exame de Prevenção do Câncer de Colo Uterino), ficando desde já marcada a consulta médica para avaliação do resultado do exame laboratorial e da conduta adequada.

Observou-se que o serviço possui uma estrutura física e humana adequada ao atendimento da clientela, contando com equipamentos modernos e profissionais especializados na área de ginecologia e oncologia, que 
atende de forma satisfatória pessoas que procuram o serviço. Os profissionais trabalham integrados na assistência da população atingida.

Obteve-se recepção positiva da equipe de saúde para realização deste trabalho, principalmente pelas enfermeiras, já que a pesquisa também faz parte dos objetivos da Instituição.

Através de Observação-Participante e acompanhamento da Consulta de Enfermagem no Ambulatório de DST, realizou-se a exploração do contexto do estudo. Nesta etapa, foram feitas observações, com a finalidade de adquirir conhecimentos sobre o fenômeno em estudo e ao mesmo tempo iniciar o processo interativo com as mulheres.

Segundo Vanzin e Nery (2000), "a Consulta de Enfermagem é a atenção prestada ao indivíduo, à família e à comunidade de modo sistemático e contínuo, realizada pela profissional enfermeira (o) com a finalidade de promover a saúde mediante diagnóstico e tratamento precoces".

$\mathrm{Na}$ Consulta de Enfermagem, verificou-se inicialmente a aplicação do histórico, que investigou dados de identificação da cliente, sua queixa principal ou motivo de ter procurado o serviço, história de doença atual, antecedentes pessoais (ginecológicos - afecções genitais anteriores; obstétricos - número de gestações, partos e abortos, quantidade de partos normais, cirúrgicos ou fórceps e data do último parto), antecedentes familiares (história de câncer na família), além de dados mais específicos da saúde reprodutiva, como: menarca, última regra, regularidade do ciclo menstrual, início da vida sexual, número de parceiros sexuais, dispareunia, sinusorragia, uso de contraceptivos e de hormonioterapia. Foi feito o Exame Físico, para observação do aspecto geral da cliente, envolvendo a inspeção de mamas e o exame ginecológico propriamente dito, quando, sob condições adequadas (com uso de equipamentos de proteção), a enfermeira fez a inspeção da genitália feminina externa e do colo do útero, introduziu o espéculo, colheu o conteúdo cervical com uma espátula para confecção da lâmina a ser analisada posteriormente e encaminhou ao laboratório. A seguir fez uso de uma pinça com algodão embebido em acido acético para facilitar a avaliação do colo uterino. Por último, foi realizado o teste de Lamm-Schiller com lugol a $5 \%$ de iodo. Todas as observações e achados clínicos foram registrados.

Percebeu-se que as consultas realizadas no ambulatório abrangeram com eficiência os aspectos relacionados à sintomatologia e à patologia das afecções genitais, entretanto, sugere-se enfatizar aspectos fundamentais a qualquer Consulta de Enfermagem, como os relacionados à satisfação das necessidades humanas básicas das clientes, suas percepções e expectativas quanto à consulta, considerar questões familiares e fatores socioculturais, muitas das vezes, determinantes na infecção das DST.

Neste momento, observou-se que as queixas mais freqüentes das clientes foram: secreção amareloesverdeada ou esbranquiçada (leucorréia) com odor fétido, dor no baixo ventre, metralgia, dispareunia, irregularidades do ciclo menstrual e prurido vulvar. A partir de uma observação mais profunda e interação com as clientes, estas demonstraram suas reações, apresentando-se tensas e ansiosas com a realização e resultado do exame, expressando medo, como mostram algumas falas referidas no momento da consulta:

"Eu morro de medo desse exame, toda vida eu faço, mas eu morro de medo de dar alguma coisa";

"Eu tô com medo, eu já vi esse exame, eu acho que dói";

“Aí meu Deus, eu não sei pra que eu inventei de não ser mais virgem, bem que eu podia ser ainda, só vou ter trabalho agora".

Naquela ocasião, buscou-se dialogar com a cliente, explicando o procedimento a ser realizado e fornecendo maior segurança e apoio psicológico.

No momento da Consulta Ginecológica, foram identificados sinais característicos de DST. Ao serem detectadas lesões sujestivas de HPV ou quando o médico, a partir dos exames solicitados, deu o diagnóstico de HPV, as clientes foram encaminhadas ao tratamento.

\section{DECISÃO - O CUIDADO COM A DOENÇA}

A segunda fase abrangeu a busca mais sistemática dos dados selecionados como mais importantes para compreender a problemática das mulheres portadoras de HPV. Acompanhou-se o tratamento de mulheres 
portadoras do HPV, realizado através da aplicação do Ácido Tricloracético (ATA 80-90\%) sobre as verrugas genitais identificadas.

Durante as interações, observou-se que as clientes demoraram para aceitar o tratamento. Quando sabem da doença, ficam assustadas, inseguras e preocupadas com o prognóstico, como demonstra-se a seguir:

"Eu fiquei desesperada em saber que não tinha cura";

"Será que se eu fizer o tratamento correto, ainda posso ficar grávida e gerar um filho saudável";

"Eu já senti melhora, eu tô doida pra ficar boa logo";

"Se eu peguei foi dele, eu só tive ele".

Percebeu-se que o diagnóstico de uma DST, na maioria das vezes, é uma surpresa acompanhada de sentimentos de medo e estigma, principalmente quando se trata de uma DST que não tem cura e que pode desencadear outras complicações, ocasionando momentos de crise consigo mesmas e dentro da família das mulheres. No decorrer do tratamento, estas ficam mais calmas e acabam aceitando e se relacionando melhor com os profissionais do serviço.

\section{DESCOBERTA}

Neste momento, tornou-se possível realizar a seleção da amostra a partir dos critérios estabelecidos. As entrevistas foram realizadas e os depoimentos analisados e codificados nas seguintes categorias: Sinais e sintomas percebidos pelas mulheres; Conhecimento das mulheres sobre as DST's; Conhecimento das mulheres com relação ao HPV; Infecção pelo HPV e relacionamento familiar; Prevenção das DST's/HPV e suas complicações; Questionamentos das clientes. As mulheres foram representadas numericamente para facilitar o processo de análise de dados.

\section{SINAIS E SINTOMAS PERCEBIDOS PELAS MULHERES}

A terceira fase buscou encontrar os princípios subjacentes ao fenômeno estudado e situar as várias descobertas num contexto mais amplo.

Os sinais e sintomas apresentados pelas participantes foram comuns, como mostram seus relatos a seguir:

"Não sentia nada, vim simplesmente fazer a prevenção" $(1,12,13,17)$;

"S enti só um carocinho e vim pra prevenção, não sabia o que era isso" $(3,4,5,8)$;

"Vim fazer uma prevenção e quando faltava alguns dias pra receber o exame senti uns carocinhos ..." $(6,2,9,14,16)$;

"Vim porque tava sentindo uma coceira que encomodava e porque meu marido tava com um carocinho, mas eu não tava sentindo nada. Ele veio fazer peniscopia e o Dr. disse que ele tava com condiloma. Aí eu vim também ..." (7).

“Tava sentindo doer, achava que era inflamação, o médico disse que eu tava com esse vírus(...) quando fiz o exame de novo não deu nada, aí depois deu essas verrugas" (10);

"Eu sentia dor no pé da barriga, corrimento, que eu achava que era inflamação (...) foi uma surpresa" $(15,11,19)$;

“Todos os anos eu faço minha prevenção e nunca deu nada (...) depois apareceu esse caroço, mas eu achava que era só uma espinha, aí eu comecei a sentir uma coceira" $(18,21)$; 
“De 3 semanas pra cá começou a aparecer uns caroços dentro e ao redor da minha vagina e cada vez coçava mais" (25).

Ao realizarem o exame, as mulheres não perceberam indicativos de DST, referindo que foram realizar o exame de prevenção rotineiramente e descobriram a infecção. Algumas notaram, mas não associaram os sinais e sintomas à sua patologia, tendo surpresa no diagnóstico da doença, o que demonstra pouco conhecimento das mulheres sobre as DST antes de iniciarem o tratamento. De acordo com Passos (2001), as escolas têm sido negligentes em lidar com os aspectos ligados à sexualidade/DST, e a família também não tem cumprido seu papel educacional, já que seus próprios líderes são desinformados.

Sob este prisma, percebeu-se que a cultura está diretamente relacionada ao conhecimento destas mulheres, pois, apesar de toda a evolução tecnológica, científica e sexual, falar sobre sexualidade e DST ainda traz estigma e sentimentos negativos. Quando surgiram, as DST foram associadas à prostituição e homossexualidade, sendo vistas como castigo divino. Hoje, as DST atingem todos segmentos da sociedade, mas mostra uma cultura de preconceito e discriminação, dificultando a conscientização e prevenção das DST no mundo moderno.

\section{CONHECIMENTO DAS MULHERES SOBRE AS DST}

Quando as participantes foram indagadas acerca do seu conhecimento sobre as DST, grande parte referiu saber apenas sobre a forma de contágio, citando a sexual como a forma mais freqüente de transmissão. Outras mulheres consideraram também outros tipos de contágio e referiram a camisinha como meio de prevenção da infecção, de acordo com as falas descritas:

"São transmitidas por causa da falta de informação, falta de prevenção e quem tem nunca se cuida e passa pra outras pessoas (...) são transmitidas através das relações sexuais" (1);

"Conhecimento mesmo não tenho, só sei que pega no ato sexual" $(2,3,8,14,16,22)$;

"Tem doença que aparece em forma de íngua, eu sei que a sífilis tem três fases e pode sumir e voltar (...) relações de sexo oral pega também, tem que usar camisinha e procurar ter um parceiro só" (6);

"A transmissão é através do sexo, tem algumas exceções, não sei se transmite pela roupa (...) se não tratar a tempo pode ter risco de não ter mais filho" (7);

"Não tenho conhecimentos" $(9,19)$;

"Tem que prevenir, usar camisinha, não pode confiar porque é marido da gente que não corre o risco" $(15,20)$;

"S ei que pega pelo sexo, o melhor tratamento é a camisinha, tanto faz com parceiro fixo ou não" $(11,12$, $14,16,18,20,21)$.

Quanto às DST conhecidas pelas mulheres, considerando que elas podiam incluir mais de uma opção, observou-se que as afecções mais citadas foram: verrugas ou crista de galo (16 mulheres), HIV ou AIDS (12), gonorréia (9), sífilis ou cancro duro (8), cancro mole (4), herpes genital (3), Gardnerela vaginales (2) e candidíase (1).

A resposta das participantes é importante, já que a introdução de práticas preventivas em relação a sua doença e às outras DST vai depender também da percepção que estas mulheres possuem acerca do seu próprio risco de evolução do HPV ou de contaminação por outra doenças. Através das respostas, percebeu-se que as participantes possuem algum conhecimento sobre as DST que mais afetam as pessoas na atualidade e a forma de prevenção, mas acabaram se contaminando. Dessa forma, o contexto da educação sexual não pode estar voltado ao modelo mecanicista, mas necessita intervir nas relações humanas, compreendendo a realidade histórica, cultural e social, através de uma conscientização das pessoas no sentido de buscarem sua saúde pela escolha pessoal. 


\section{CONHECIMENTO DAS MULHERES COM RELAÇÃO AO HPV}

As participantes informaram que receberam poucas informações sobre sua doença, quando foram encaminhadas ao tratamento. Mas relataram o que aprenderam no decorrer do tratamento:

"S ei que pode apresentar coceira, aparece um carocinho e se você não prevenir pode aumentar (...) já conversei com muita gente, mais cada um diz uma coisa diferente e você fica confusa" (1);

"S ei que é condiloma, vírus HPV, que existe vários tipos (...) não sei mais nada" (3);

"A única coisa que eu sei é que são as principais causadoras do câncer de colo de útero e pode provocar HIV" (4);

"S ei que depende de cada organismo e se você não tratar logo pode virar câncer e morrer ..." (7);

"Não sei nada sobre a doença" $(2,5,8,9)$;

"HPV nunca ouvi nem falar (...) o médico disse que pega na relação" (10, 14, 19, 20);

"Apesar de ter estudado confesso que não sei quase nada, fiquei sabendo recentemente que pega pelo parceiro" (15);

"Depois que comecei a me tratar conversei com muitas Dras (...) pode ser que pegue de roupas íntimas, tem controle, mas não tem cura" $(21,16)$;

"Pode pegar no ânus, internar no útero e virar um câncer, pode também não ter cura" $(6,25)$.

As mulheres demonstraram interesse em adquirir conhecimentos sobre sua doença. Algumas procuraram se informar sobre $o$ assunto, pesquisando em revista ou conversando com outras pessoas, porém, suas dúvidas muitas vezes não foram esclarecidas.

\section{INFECÇÃO PELO HPV E RELACIONAMENTO FAMILIAR}

Através das entrevistas e conversas, percebeu-se que a descoberta da doença causa um impacto muito forte na sexualidade das mulheres, e conseqüentemente, nos seus relacionamentos, trazendo sentimentos de raiva e aversão pelo parceiro.

Para algumas clientes, o surgimento da doença afetou fortemente os seus relacionamentos, havendo 0 afastamento das mulheres de seus parceiros, demonstrado nas expressões:

"Por enquanto acabou. Sei de quem foi, não continuo mais com ele, acabei por causa disso, mas não disse pra ele" (4);

"Não estou fazendo (sexo), depois que apareceu isso eu deixei o homem (...) eu não quis mais conversa com ele, eu quero mais que ele morra, ele tem outra mulher" (11);

"Se eu peguei foi dele, pois eu só tive ele, depois que eu pequei a doença eu tratei de evitar (...) eu mandei ele embora, mas eu não podia fazer isso por causa dos filhos, eu pedi pra ele não me procurar mais" (19).

E m outras situações, as mulheres optaram por não manterem relações sexuais com os seus parceiros durante 0 tratamento, com a finalidade de contribuir na terapêutica e posteriormente se recuperarem no plano afetivo:

"Por enquanto eu não tô tendo relação, meu marido não detectou o vírus" $(3,9,10,14,18)$; 
"Mudou quando eu soube da doença, porque eu parei de me relaciona, eu fiquei muito tempo decepcionada com ele" (16).

As participantes relataram ainda insegurança com relação aos seus relacionamentos conjugais. A doença trouxe desconfiança sobre a fidelidade do parceiro, o que gerou em alguns casos uma crise familiar:

"No começo mudou porque a gente conversou e a mulher fica naquela dúvida, eu sei que eu peguei dele, eu fico temerosa, pedi pra ele se tratar" $(17,18,21)$;

"Eu quis me separar, depois convenci a ele vim pro tratamento (...) no começo mudou o comportamento na relação sexual, fico insegura, perdi a confiança" (6);

"Me senti assim (...) sabe quando você não espera, já tem 4 anos que eu tô com ele, é meu primeiro namorado, só transava de camisinha (...) me senti muito abalada" (7);

"No início eu fiquei com raiva dele, quis até me separar, eu chorava muito, eu ficava pensando que hora ele tinha me traído se eu tava com ele o tempo todo, minha cabeça bloqueou, eu perdi quase totalmente o tesão, ele me entendeu" (12).

Percebeu-se que a maioria das mulheres não contou com o apoio de seus parceiros no tratamento, mesmo sendo este fator facilitador no enfrentamento da situação, como refere a fala:

"Meu relacionamento permaneceu o mesmo, continuei com camisinha, mas no dia de tratamento eu não faço. Contei pro meu marido e minha mãe. Me aconselharam a ficar indo pro tratamento e conversar com ele (marido). Ele foi e não deu nada" (1).

Diante dos depoimentos, é relevante compreender como fatores sociais e culturais operam na construção das relações de gênero. F reire (1980) refere que "Cultura é todo o resultado da atividade humana, do esforço criador e recriador do homem, de seu trabalho por transformar e estabelecer relações de diálogo com os outros homens".

\section{PREVENÇÃO DAS DST/HPV E SUAS COMPLICAÇÕES}

As participantes foram questionadas ainda relativamente à prevenção das DST/HPV e suas complicações, sendo obtidas as seguintes respostas:

"Penso que vou seguir rigorosamente o tratamento, vou fazer tudo do jeito que a Dra. (enfermeira) mandar. Não pretendo ter relação no tratamento nem de camisinha. 0 que eu quero é ficar boa" $(1,5,7$, $10,15,19,21,24)$;

"Vai ser difícil (...) vou usar camisinha, ficar cuidando da minha saúde e ter uma alta logo" (8, 9, 14, 16, 17, 20, 22);

"Vou continuar no tratamento e conversar com a ginecologista pra saber mais alguma coisa" $(2,4,11)$;

"Quero ficar fazendo prevenção, vindo sempre ao ginecologista e ficar se vigiando" (3,6);

"Não vou usar roupa de amiga, nem sentar mais em vaso de outros lugares, usar camisinha, ir procurar logo o médico quando aparecer algum sintoma, se tratar, fazer asseio para não pegar inflamação, ter boa a limentação, fazer planejamento familiar, estudar mais sobre as doenças e conversar com os jovens que eu conheço" $(12,25)$.

Percebeu-se que as mulheres pretendem continuar realizando o tratamento, apesar das dificuldades encontradas (crise familiar, emprego, tratamento longo), e que, vinculadas a este, consideram o uso da camisinha como um fator importante na prevenção das DST, mostrando-se interessadas na promoção de sua saúde. 


\section{QUESTIONAMENTOS DAS CLIENTES}

Ao final de cada entrevista, as participantes puderam fazer perguntas acerca do que gostariam de saber sobre sua doença, sendo suas dúvidas descritas abaixo:

"Quero saber se pode virar câncer" $(2,8)$;

"Tinha vontade de saber se a gente nunca fica boa, você sabe se tem cura?" $(2,3,6,7,10,11,12,13$, $14,17,20,21)$;

"Pode ficar boa usando pomadas?" (8);

"Eu fiquei desesperada (...) só vi o pessoal aqui falando que não tinha cura" (12);

"Só pega na relação sexual ou tem outras formas?" (9, 11, 13, 14, 21);

"Eu queria saber se transmite pela toalha, se deitar na mesma rede, pelo vaso sanitário, pelo sabonete ..." $(4,6,18)$.

Foi possível detectar que a maior preocupação das participantes é com relação à cura da doença e se há outra forma de transmissão para o vírus HPV que não a via sexual.

Durante a pesquisa, as mulheres foram esclarecidas de que a doença pode ser controlada, sobre a importância da regularidade no tratamento e dos riscos da evolução da doença se não for acompanhada de forma adequada.

\section{CONSIDERAÇÕES FINAIS}

Observou-se que o HPV no contexto das DST passou por diferentes fases, sendo inicialmente vista como uma patologia desvinculada das doenças sexualmente transmissíveis, evoluindo posteriormente para um conceito de DST com alta incidência e com fatores predisponentes ao desenvolvimento do câncer.

Durante toda a trajetória do HPV, constatou-se que os estudos voltados para a classificação, tratamento e notificação tiveram avanços significativos. Entretanto, verificou-se que as medidas preventivas envolvendo educação em saúde não tiveram o mesmo sucesso, pois contamos com um número crescente de casos de pessoas se contaminando com o vírus.

Através da observação de Consultas de Enfermagem no Ambulatório de DST, percebeu-se a necessidade da inclusão da Educação em Saúde no atendimento a pessoas portadoras de DST. No acompanhamento ao tratamento, verificou-se a forte influência da descoberta da doença no contexto cultural das mulheres e nos seus comportamentos relacionados à sexualidade.

Torna-se difícil trabalhar a Educação em Saúde quando não se incluem as políticas públicas, ambientes apropriados e reorientação dos serviços de saúde atrelados a propostas pedagógicas libertadoras, comprometidas com o desenvolvimento da solidariedade e da cidadania, pois é notória a preocupação com a tecnologia positivista, entretanto, sabe-se que o ideal seria fazer com que a população percebesse a importância da E ducação em Saúde em suas vidas e adotasse um comportamento que lhe proporcionasse melhor qualidade de vida.

Diante do exposto, sentiu-se a necessidade e importância de trabalhar a Educação em Saúde em torno do comportamento sexual das pessoas, com a finalidade de reduzir a contaminação pelo HPV.

ABSTRACT: Studies on sexually transmissible diseases show that $90 \%$ of the women with intra-epitelial cervical cancer are carriers of the papiloma human virus (PHV). It was objectified to investigate the prevention of the evolution of PHV in women in the family cultural context. An ethnography approach was used, tends as theoretical support Ludke and André during the exploration, decision and discovery phases. Through participative activity and dialogued, 25 women were interviewed. It was noticed that PHV caused a very strong impact in the family structure and that most of the women didn't count with the its partners' support in the treatment. It was concluded 
by the importance of working the education in health around the people's sexual behavior, with the purpose of reducing the contamination for $\mathrm{PHV}$.

KEY WORDS: Sexually transmited diseases; Women; Family; Papillomavirus human

RESUMEN: Los estudios acerca de enfermedades sexualmente transmisibles mostran que $90 \%$ de las mujeres com neoplasia intra-vervical son portadoras del papiloma virus humano (HPV). Nuestro objetivo es investigar la prevención de la evolución del HPV en mujeres en el ámbito de la família. Se utilizó un abordaje etnográfico com fundamentación teórico de Ludke y André en las fases de exploración, decisión y descubierta com la participación interactiva de las 25 mujeres entrevistadas. Se percibió que el HPV produzco un impacto muy fuerte en la estructura familiar y que la mayoría de las mujeres no tuvo el apoyo de sus compañeros en el tratamiento. Se concluye que es importante el trabajo educativo abordando el tema comportamiento sexual de las personas com la finalidad de reduzir la contaminación por el vírus.

PALABRAS CLAVE: Enfermedades sexualmente transmisibles; Mujeres; Familia; Papillomavírus humano

\section{REFERÊNCIAS}

1 ANDRÉ, M. E. D. A. Etnografia da prática escolar. 6. ed. Campinas: Papirus, 2001.

2 BARDIN, L. Análise de conteúdo. Lisboa: Edições 70, 1977.

3 BARBOSA, R. H. S. As mulheres, a AIDS e a questão metodológica: desafios. In: CZESRENIA, D. et al (Org.). AIDS: pesquisa social e educação. São Paulo: HUCITEC, 1995. p. 65-83.

4 BARROSO, M. G. T, SOUSA, L. I. E. X.; FROTA, M. A. Etnografia e Enfermagem: uma experiência da pós-graduação em enfermagem- UFC. Rev. Rene. v. 2, n.2, p.15-24, jul./dez. 2001.

5 BRASIL. Conselho Nacional de Saúde. Aspectos éticos da pesquisa envolvendo seres humanos. Resolução 196. Brasília, 1996.

6 FREIRE, P. Conscientização: teoria e prática da libertação: uma introdução ao pensamento de Paulo Freire. 3. ed. São Paulo: Moraes, 1980.

7 J ACYNTO, C.; ALMEIDA FILHO, G. HPV infecção genital feminina e masculina. Rio de J aneiro: REVINTER, 1994.

8 LARAIA, R. B. Cultura: um conceito antropológico. 11. ed. Rio de J aneiro: Zahar, 1997.

9 LEININGER, M. M. Culture care diversity \& universality: a theory of nursing. New York: National League for Nursing Press, 1991.

10 LUDKE, M.; ANDRÉ. M. E. D. A. Pesquisa em Educação: abordagens qualitativas. São Paulo: EPU, 1986.

11 PASSOS, M. R. L. et al. DST: Doenças sexualmente transmissíveis - se educar, dá para evitar! 2. ed. Rio de J aneiro: Revinter, 2001.

12 RAMADAM, A. B. A. ; ABDO, C. H. N. Sexualidade-trâmites, percalços e desvarios. In: ABDO, C. H. N (Org.). Sexualidade humana e seus transtornos. 2. ed. São Paulo: Lemos-E ditorial, 2001. Cap.I. p. 13-22.

13 RIBEIRO, A. M. S. Crenças e valores da mulher portadora de papiloma vírus humano-HPV: abordagem na etnoenfermagem. Fortaleza, 1998, 98 p. Dissertação (Mestrado) - Curso de Mestrado em Enfermagem, Universidade Federal do Ceará.

14 VAITSMAN, H. Mais um motivo para usar camisinha. J ornal do Comércio, Recife, 24/maio, 1998. p. 1

15 VANZIN, A. S.; NERY, M. E. Consulta de enfermagem: uma necessidade social? 2. ed. Porto Alegre: RM \& L Gráfica e Editora, 2000. 